\title{
Study on underwater connector temperature and pressure testing technology
}

\author{
Jun Liu1, a , Yuchen Wang, ${ }^{2, b}$, Baoshuang Shi, ${ }^{1, a}$, Daoming Wang ${ }^{2, b}$, Liquan \\ Wang $^{1, a}$, Xiangjuan $\mathrm{Xu}^{2, \mathrm{~b}}$ \\ ${ }^{1}$ Harbin Engineering University, Harbin, China \\ ${ }^{2}$ OFFSHORE OIL ENGINEERING CO.LTD, Tianjin, China
}

Keywords: underwater connector; test standard; temperature and pressure test device; finite element analysis

\begin{abstract}
: the paper has researched the relevant authority standards of domestic and international such as ISO 10423, ISO 13628, API SEPC 17D, ISO 13679, ISO 21329, API Spec 6A, then determined the designed parameters of the temperature pressure test connector. And, the test device was designed according to the test requirement. The device is consist of heating unit, cooling unit and insulation unit. Finally, select heating the oil tank as the heating method, vaporization of the liquid nitrogen as the cooling methods, insulation materials and temperature compensation as the heat maintaining method. Ansys simulation was performed for the testing procedure. Reliable temperature gradient of the testing was obtained. At last, some suggestion was presented for the temperature control difficulty in the testing.
\end{abstract}

\section{Introduction}

Underwater production system is the main stream of underwater oil and gas field development model ${ }^{[1]}$, the deep water pipeline connection technology is need to be solved in subsea production system research ${ }^{[2 \sim 4]}$.For deep water oil and gas pipeline connection, mechanical connection is most used. Mechanical connection techniques commonly contains bolted flange connection, the clamp connection and the jaw type connection, etc. ${ }^{[5]}$.As part of the Christmas tree or underwater oil and gas pipeline, Underwater connector is mainly used for pipe manifold connection and quick repairing ${ }^{[6]}$.In the internal of Connector is often high temperature and high pressure liquid, or vapor liquid mixture, Outside of the connector is the low temperature water, so the temperature and pressure performance is the core of connector. The performance on temperature and pressure must be carried out ${ }^{[7]}$.

\section{Underwater connector temperature and pressure test steps}

In the test process, according to the requirements of API 6 A, F. 1.11 the temperature changes shall be carried out to response to monitor and control on the implementation of test pressure. Specific experimental steps, the whole process is shown in figure 1:

a. To start test at room temperature and pressure, temperature rises until the highest temperature of the test requirement;

b. When the highest temperature is stable in the test. To provide the test pressure, and to maintain the pressure at least $1 \mathrm{~h}$, then relief pressure;

c. To reduce the temperature to the limit of test lowest temperature;

d. To provide test pressure, to maintain at least $1 \mathrm{~h}$, then relief pressure; 
e. To improve temperature to room temperature;

f. To provide test pressure at room temperature, to improve the temperature until the highest test temperature ,During this time, to control test pressure maintain the limit pressure of 50\% to $100 \%$

g. To hold Pressure in the test pressure, and to maintain at least $1 \mathrm{~h}$;

h. To reduce the temperature to the lowest temperature and to control test pressure in a limit test pressure of $50 \%$ to $100 \%$ in the process;

i. To keep the test pressure, and to hold time at least $1 \mathrm{~h}$;

j. To rise temperature to room temperature, and to control test pressure maintain the limit pressure of $50 \%$ to $100 \%$;

$\mathrm{k}$. To relief pressure, and then to rise the temperature to the highest test temperature;

1. To Provide test pressure, at least $1 \mathrm{~h}$, then decompression;

$\mathrm{m}$. To reduce the temperature to the lowest test temperature;

$\mathrm{n}$. To provide test pressure, at least $1 \mathrm{~h}$, then the decompression;

o. To Improve the temperature to room temperature;

p. To Provide test pressure, at least $1 \mathrm{~h}$, then the decompression;

q. To provide $5 \%$ to $10 \%$ of the test pressure, at least $1 \mathrm{~h}$, then to release the pressure release.

\section{The requirements of underwater connector temperature and pressure test}

In this paper, we have studied 6 inch card claw type, bolt flange and clamp connector underwater test on temperature and pressure. Through the national standard GB/T 22513-22513, it concluded that the performance of three kinds of underwater connector as shown in table 1.According to the temperature test requirements of API 6, the level of test temperature range is the rated temperature rating, between $18{ }^{\circ} \mathrm{C} \sim 121{ }^{\circ} \mathrm{C}$. Also in API 6 , the method of temperature load and the stability of temperature are required. According to the actual situation, the connector is adopted to improve the heating by internal system, but the low temperature load must be applied on external connector; Also required the temperature stability in the process of temperature test, the temperature should reach or exceed the test temperature in the process ,the heating and cooling temperature shall not exceed the testing temperature of $11{ }^{\circ} \mathrm{C} \quad$ [8].To start the holding stage after temperature stability, and the device under test is separated from the pressure source, pressure maintaining time should comply with the test requirements. In the holding stage, the pressure change rate should be less than $5 \%$ of the test pressure per hour, or $500 \mathrm{psi} / \mathrm{h}$ (in both the minimum standard).If the rate of temperature change is less than $0.5{ }^{\circ} \mathrm{C} / \mathrm{min}$, then look the temperature as stable.

Table1 underwater connector performance ${ }^{[9]}$

\begin{tabular}{|c|c|c|c|c|c|c|}
\hline & \multirow{2}{*}{$\begin{array}{c}\text { The } \\
\text { sheel } \\
\text { of } \\
\text { pile }\end{array}$} & $\begin{array}{c}\text { Prodifi } \\
\text { cation } \\
\text { level }\end{array}$ & $\begin{array}{c}\text { pressure } \\
\text { rating }\end{array}$ & $\begin{array}{c}\text { pressure }(\mathrm{MPa}) \\
\text { the rated working } \\
\text { pressure }\end{array}$ & $\begin{array}{c}\text { temperature } \\
\text { rating }\end{array}$ & the temperature scope \\
\hline 152.4 & 11 & PSL3 & 3 & 34.5 & $\mathrm{U}$ & $-18-121$ \\
\hline
\end{tabular}


The temperature test device of underwater connector. The temperature of the device working mode has four kinds: high temperature heating, cooling, constant temperature and low temperature constant temperature mode. The start of the work model is controlled by the testing steps and process designing, but the end of model is controlled by the achievement of the tasks.

Due to the temperature test was conducted with pressure test, so to use hydraulic oil heat the test sample; Due to the high and low temperature difference is too big, the general refrigerator machine can't work, so to use liquid nitrogen vaporization to cool sample; The Principle of temperature testing device is shown in figure 1.

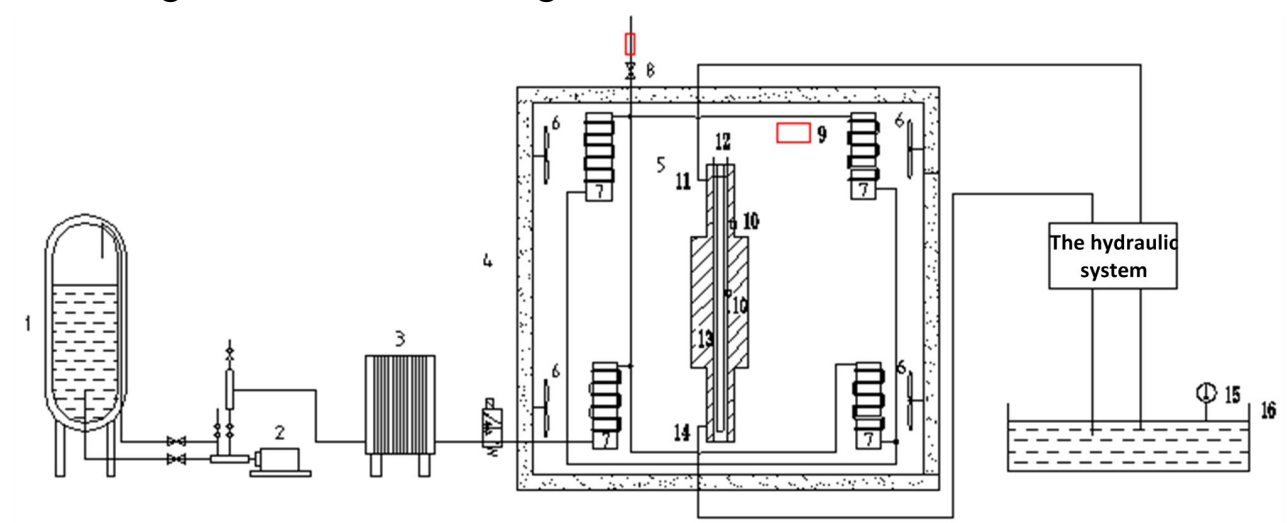

1.liquid nitrogen storage tank 2.cryogenic liquid pump3.carburetor 4.two two-way solenoid valve 5.sealing temperature test box 6.fan 7.heat exchanger 8.nitrogen temperature sensor 9.air temperature sensor 10.connector temperature test sensors 11.oil entrance 12.heater 13.the connector under test 14.oil export 15-thermometer 16.tank

Figure 1 temperature testing device schematic diagram

Heating mode: open the internal heater 12 of connector in order to improve the hydraulic oil temperature, to rise the temperature of test sample through convection heat transfer .To control test temperature not to exceed the requirements of testing standard. To control the high temperature of hydraulic oil range $121{ }^{\circ} \mathrm{C}$ to $131{ }^{\circ} \mathrm{C}$ by controlling the heater power. To turn off the heating mode while the underwater connector reach to test temperature.

The high temperature insulation mode of temperature testing device should start in the high temperature and pressure maintaining phase, namely when the temperature falls, opening the internal connector heater 12 , make the test sample temperature stable by controlling the heater power to meet its heat loss.

To open variable pump 2 and nitrogen vaporizer 3 in the cooling mode, and to control low temperature nitrogen flow into the cooling pipe through two-way solenoid valve 4 . Real-time monitoring of cooling pipe import and export temperature and the air temperature in the cabinet and the test sample temperature, to Control variable pump flow at low temperature, in order to control cooling mode of power. When the temperature of test sample reach to the low temperature, to close the solenoid valve 4 , the variable pump 2 and nitrogen gas vaporizer 3 .

The pressure test device of underwater connector. There are five kinds of working modes in pressure system: Oil supply mode, pressure mode, the holding pattern, Control pressure mode and pressure relief model. The start of the work model is controlled by the testing steps 
and process designing, but the end of the model is controlled by the achievement of the tasks. Pressure control system's main goal is two points: the pressure transformation inside the test sample. While the temperature change, to complete the corresponding pressure change. Oil supply mode has two purposes: one is supply oil into system in the pressure test, the connector and the hydraulic system will be filled with hydraulic oil; another is to provide hydraulic oil to test sample, improve the pressure of the test sample in the press test. Pressure model is used to apply pressure to the test sample in the pressure test, to ensure that the internal pressure of connector reaches a certain pressure. The holding pattern refers to the working pressure reaches the required test pressure and into the stable state. The Test samples and pressure system power disconnect at this time. Pressure control mode is used for temperature and pressure cycle test stage, the pressure control system is $50 \% \sim 100 \%$ of the test pressure. Pressure relief model is used for the system goes to zero after pressure test and then the hydraulic oil recovery to the tank.

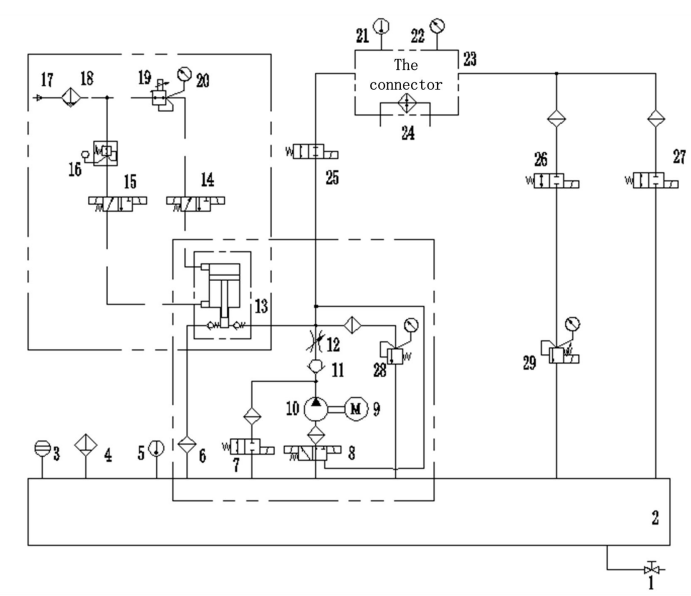

1. stop valve 2.the fuel tank 3.level gauge 4.air filter $5 \& 21$ thermometer 6.filter 7, 25, 26, 27.electromagnetic valve 8.two-way solenoid valve 9.motor 10 .hydraulic pump 11.check valve 12.throttle valve 13.gas-liquid booster pump 14,15.two-position three-way solenoid valve 16.pressure regulating valve 17.driven air 18.air filter 19.proportional pressure regulating valve 20,22.pressure gauge 23.connector 24.temperature regulator 28 -straight moving type relief valve 29-electromagnetic relief valve

Figure 2 hydraulic principle diagram of temperature pressure test device

This system has two parts demand for pressure control. Firstly, the system needs a variety of stable pressure. Secondly is to control the pressure within the scope of the requirements.

In figure 3, 28 as the system relief valve, it can ensure the system pressure does not exceed the scope; The hydraulic solenoid valve 27 as outlet switch, is used for unloading of the test sample. In figure, one-wayvalve 12 can provide protection to dosing pump 10 , avoid high-pressure gas-liquid booster pump 13 make its inversion; In addition, in order to achieve the control of pressure and temperature in the corresponding position, place the pressure gauge and thermometer.

Large flow rate high pressure pump set by a large and medium pressure flow quantitative pump 10and gas-liquid booster pump 13. The two pump is used for oil supply, pressure supply two actions in order.

The system in oil supply mode. Quantitative pump 10 work, 13 gas-liquid booster pump does 
not work. The system start for pressure mode at the end of the oil supply mode, the electromagnetic valve 8 closed at this point. The oil mass pump group provide to the system is quantitative pump 10 flow.

When the system at the end of the oil supply mode, start for pressure mode. the electromagnetic valve 8 open at this point, Quantitative pump 10 oil flow back into the tank, does not supply oil to system; Gas-liquid booster pump 13 work, provides pressure to the system, increases the system pressure; Until the system pressure reaches the test pressure and turn off the pressure model, closed the electromagnetic valves 25 . The system goes into the holding pattern.

\section{The temperature and pressure cycle test plan of underwater connector}

The temperature and pressure test system is designed to have five pressure test patterns and four kinds of temperature test mode integrated test system. Through the different work mode and alternatively working to complete the testing process .Because each test step is different, the working mode of testing process is different. Analyze every test step, look every work pattern as a unit to design and analyze the test workflow, which can better understand the every detail in the process of testing, on the temperature and pressure test system for the next step and can provide design basis for the detailed design.

Table 2 temperature and pressure cycle test

\begin{tabular}{|c|c|c|c|}
\hline Sub processes & $\begin{array}{c}\text { variable temperature } \\
\text { discontinuous stress } \\
\text { tests }\end{array}$ & $\begin{array}{c}\text { variable temperature } \\
\text { continuous stress } \\
\text { tests }\end{array}$ & $\begin{array}{c}\text { room temperature } \\
\text { stress test }\end{array}$ \\
\hline test steps & a-e $\quad \mathrm{k}_{2}-\mathrm{o}$ & $\mathrm{f}-\mathrm{k}_{1}$ & $\mathrm{p}-\mathrm{q}$ \\
\hline
\end{tabular}

Temperature and pressure cycle test workflow:

The cycle test process of temperature and pressure is so complex that it is difficult to describe the test workflow one time. So the test is divided into several sub tests, to bridge the child test in chronological order, then to complete testing.

Temperature and pressure cycle test can be divided into three sub test. Every steps of the test are shown in table 2. The step $\mathrm{k}$ is divided into $\mathrm{k} 1$ and $\mathrm{k} 2$. While, $\mathrm{k} 1$ is pressure relief and $\mathrm{k} 2$ is temperature rise. The four subsystems test run according to the order of the figure 4 is the temperature and pressure cycle test.

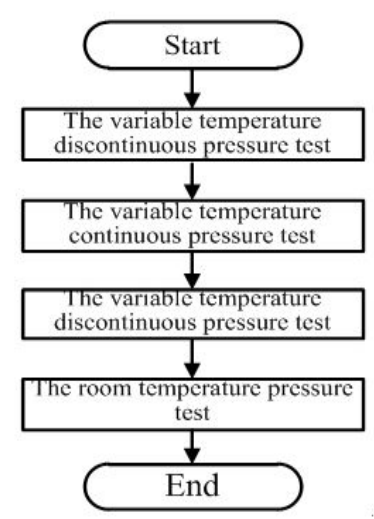

Figure 3.The test sequence diagram of temperature and pressure cycle test 
Corresponding variable temperature discontinuous stress tests in figure 3 is made up of a high temperature and pressure test and a low pressure test, but the temperature and pressure are not coupled together for testing. The working process is shown in figure 4.

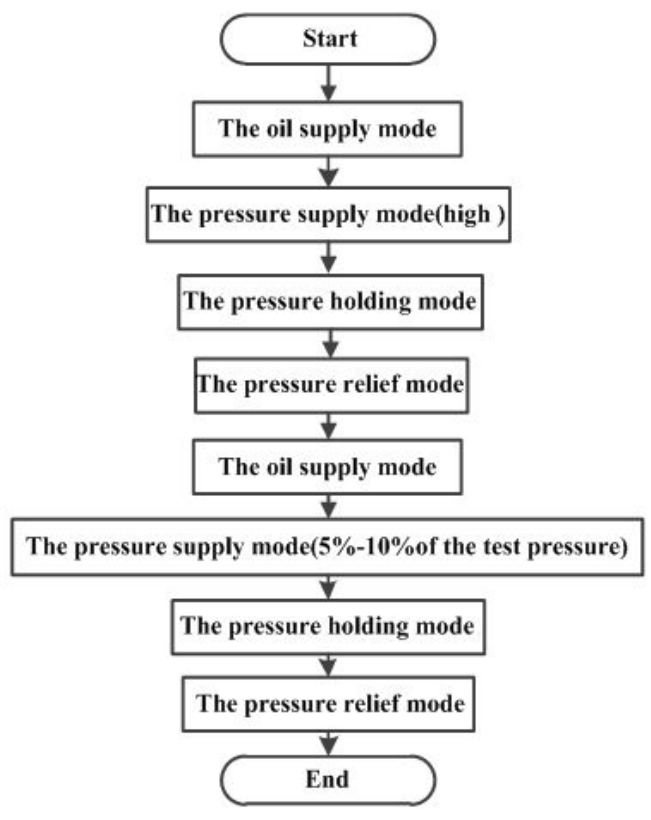

Figure 4.Intermittent pressure test flow chart on Variable temperature

Variable temperature continuous pressure test is made of a high temperature and pressure test and a low pressure test, when working in the heating mode and cooling with pressure control mode, namely the two tests of temperature and pressure are coupled together. The work process is shown in figure 5.

Room temperature pressure test is consist of a high pressure test and a low pressure test, and without temperature model in the test process, keep at room temperature Test work- flow is shown in figure 6.

The process includes temperature discontinuous pressure test, continuous pressure variable temperature tests. Temperature intermittent pressure and room temperature stress testing four parts. And the complete temperature and pressure test process need to carry out the cycle three times, until the test sample has not leak or damage in the process of temperature and pressure under the condition of the test piece, the test is successful. Otherwise the test fails, need to replace the corresponding component test again 


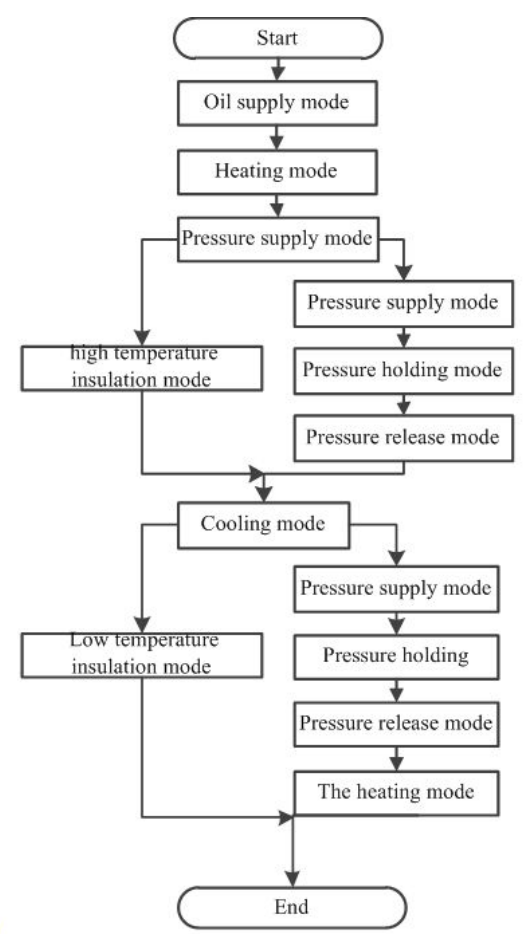

Figure5.The flow chart of variable temperature continuous pressure test

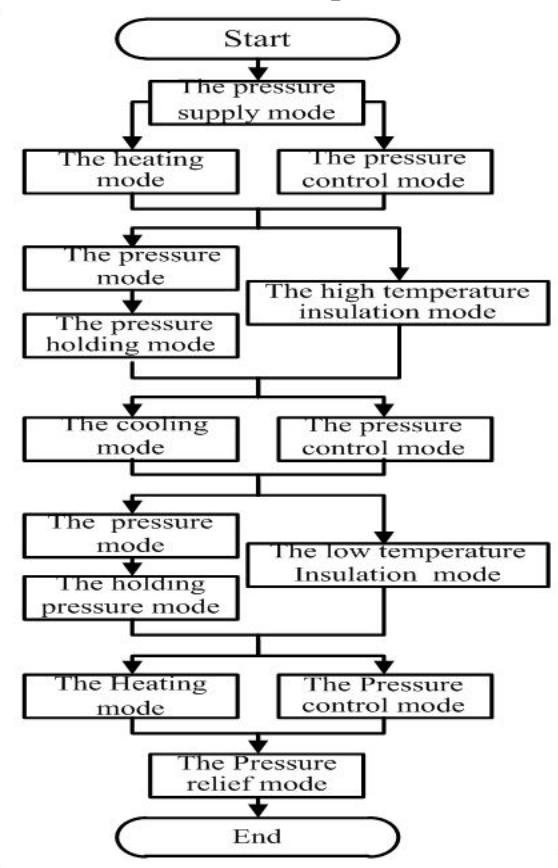

Figure6. The flow chart of room temperature pressure test

\section{The temperature-changing process simulation of underwater connector}

The test sample is not a whole in the process of calculating the temperature-changing of test sample, so the temperature of test sample close to the heat transfer surface is changing quickly. While the temperature of distant part changes slowly, in order to understand the actual temperature changes in the process of simulation, Using the transient heat transfer module of Ansys Workbench simulation the heat-exchange process. First of all, the mesh of test sample is shown in figure 7. 


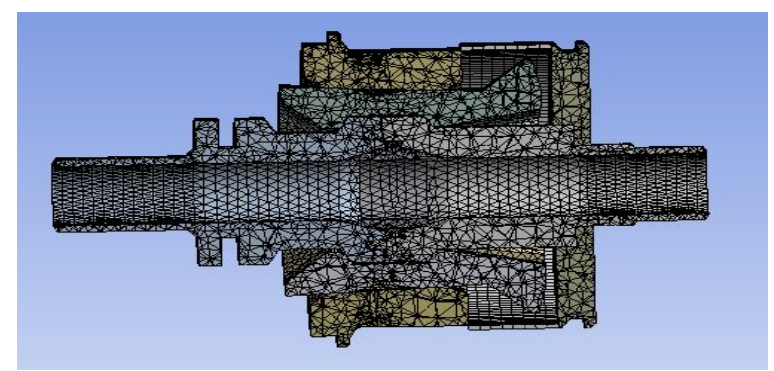

Figure7.The mesh of test sample

The simulation of heating process. Easy for calculating, hypothesis the temperature of hydraulic oil inside the test sample is constant, $130{ }^{\circ} \mathrm{C}$, without considering the heat conduction between the test sample and the outside air. The initial temperature is set to $18{ }^{\circ} \mathrm{C}$. The test sample temperature rises from $-18{ }^{\circ} \mathrm{C}$ to $121{ }^{\circ} \mathrm{C}$; The calculation result is shown in figure 8.The highest temperature and minimum temperature time curve of the test sample is obtained at the same time, as shown in figure 9.

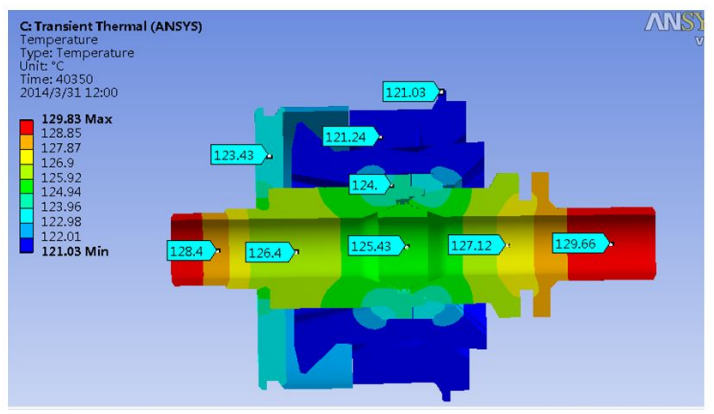

Figure8. The heating temperature nephogram

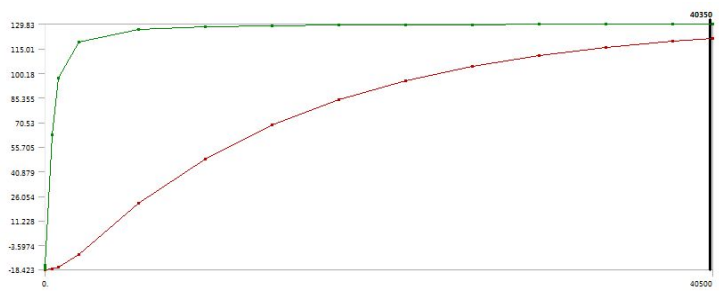

Figure9.The heating temperature curve

Can be clearly seen from the figure 8 and 9 , in the 40350s, the temperature of all parts above $121{ }^{\circ} \mathrm{C}$, showing that temperature rising test completed.

The simulation of cooling process. Easy for calculating, hypothesis the temperature of outside test sample is constant, keep at $-29{ }^{\circ} \mathrm{C}$, and without considering the heat conduction between the test sample and the outside air. the temperature of the sample reduce from $121{ }^{\circ} \mathrm{C}$ - $18{ }^{\circ} \mathrm{C}$ in cooling test, set the initial temperature to $121{ }^{\circ} \mathrm{C}$; The calculation results is shown in figure 10.The highest temperature and minimum temperature time curve of the test sample is obtained at the same time, as shown in figure 11. 


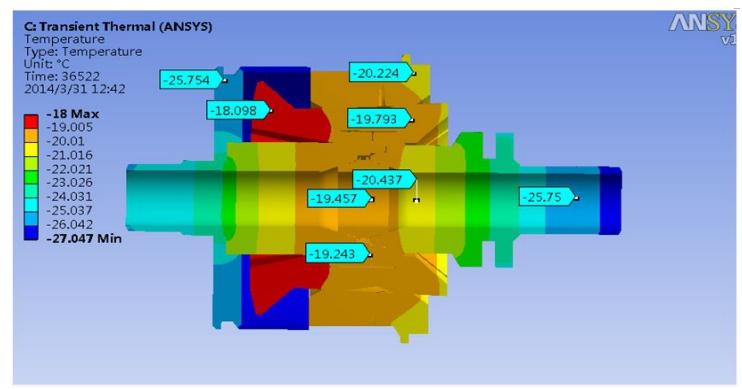

Figure10.The temperature nephogram in cooling process

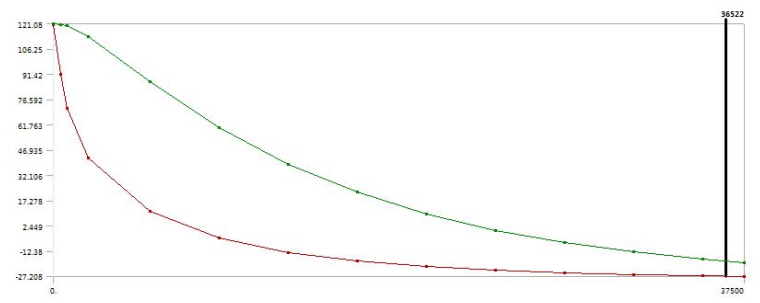

Figure11.The temperature curve in cooling process

Can be clearly seen from the figure 10 and 11, in the $36522 \mathrm{~s}$, all parts of the test sample are reach to the test low temperature, below 18 degrees. It showed that the test in cooling stage was completed.

\section{Acknowledgment}

The high technology marine scientific research project of ministry, "underwater connection system and key equipment"

\section{Summary}

This paper has studied the domestic and international standards of underwater connector. It has determined the underwater connector testing temperature range and testing requirements. According to the standard, we have carried out the detailed design for underwater connector temperature test device. Firstly, the temperature testing device is divided into heating unit, refrigeration unit and heat preservation unit: There are also 4 kinds of working mode: Heating, cooling, high temperature and constant temperature, low temperature constant temperature mode And temperature testing principle was analyzed and the way of their work; Secondly it put forward 5 kinds of working mode, the oil supply mode, the pressure supply mode, The holding pattern pressure, the pressure control and pressure relief model; this paper has also carried on the finite element analysis to variable temperature process of test sample, it has determined the temperature test process temperature load is determined. 


\section{References}

[1] Mou Yongchun etc. Discussions on deep sea engineering technology research [J]. Journal of petroleum engineering construction: 2008: 26-29.

[2] Wang Jianwen, Wang Chunsheng \& Yang Siming. Underwater production system development model and engineering design [J]. Journal of China shipbuilding.2011, 52:27-33.

[3] Thomas Bernt \& Endre Smedsrud. Ormen Lange Subsea Production System[J].Proceedings of the 2007 Offshore Technology Conference, Houston, USA, Apr 30-May 3, 2007: OTC 18965.

[4] K.E.Apeland, J.O. Berge, R. Verley M Armstrong \& N. Woodward [J]. Deep water remote welding technology for pipeline repair and hot-tapping. DOT. 2006.

[5] Shi Li Xia etc. 2011. The submarine pipeline tieback technology [J]. Journal of natural gas industry, 2011, 28 (5): 1-3.

[6] Liao Mosheng \& Yang Benling. 2007. New characteristics of the world's oil equipment development and the opportunities and challenges [J]. Oil field machinery.2007, 36 (9): 1-6.

[7] Li Xuefu \& Pan Bin. Development of offshore oil and gas-technology picks of chengdao crude [M]. Shanghai: Shanghai jiao tong university press 2009 (1): 27-40.

[8] API Spec6A.Specification for Wellhead and Christmas Tree Equipment[S].API,2010 : 281-303.

[9] GB/T22513-2008.Oil and natural gas industries-design and operation of subsea production system [S]. Beijing: China standard press, 2005:52-79. 